\title{
Giant Gallbladder Presenting as a Right Iliac Fossa Mass Removed by Mini-laparoscopic Cholecystectomy
}

Joshua Fultang ${ }^{1}$, Ugochukwu Chinaka ${ }^{2}$, Abdulmajid Ali ${ }^{1}$

1. General Surgery, University Hospital Ayr/University of West of Scotland, Ayr, GBR 2. General Surgery, University Hospital Ayr/University of West of Scotland, AYR, GBR

Corresponding author: Abdulmajid Ali, abdulmajidali@hotmail.com

\begin{abstract}
Giant gallbladder (GGB) is a rare condition that can result from cholelithiasis or chronic cholecystitis. Although there are no clear-cut definitions, gallbladders of $>14 \mathrm{~cm}$ and $\geqslant 1.5 \mathrm{~L}$ have been regarded as GGBs. To date, most GGBs have been managed by laparotomic removal. This report describes a patient with a GGB that presented as a right iliac fossa mass. The GGB was successfully removed by mini-laparoscopic cholecystectomy. A 63-year-old woman presented with painful swelling in her right lower abdomen associated with dyspepsia and a palpable right iliac fossa mass. Computed tomography of the abdomen revealed a markedly enlarged gall bladder $(19.5$ x 5.4 x $5.6 \mathrm{~cm})$ containing stones. Magnetic resonance cholangiopancreatography ruled out extra- and intrahepatic ductal dilatation and stones. She underwent a mini-laparoscopic cholecystectomy, and her postoperative recovery was uneventful.
\end{abstract}

Received 07/30/2019

Review began 09/02/2019 Review ended 09/03/2019 Published 09/05/2019

() Copyright 2019

Fultang et al. This is an open access article distributed under the terms of the Creative Commons Attribution License CC-BY 3.0., which permits unrestricted use, distribution, and reproduction in any medium, provided the original author and source are credited.
Categories: Miscellaneous, Gastroenterology, General Surgery

Keywords: gallbladder, gallstones, laparoscopic cholecystectomy, mini laparoscopic cholecystectomy, giant gallbladder

\section{Introduction}

Giant gallbladder (GGB) is a rare condition, and as of 2014, only eight cases have been reported in the literature since the 18th century [1,2]. A case report in 2013 described details, including gallbladder dimension in four patients with GGBs [2]. Attempts have been made to define GGBs by weight, volume, and shape. Most patients to date have undergone laparotomy for removal of GGBs [3]. This report describes a patient with a GGB presenting as a right iliac fossa mass. The GGB was successfully removed by minilaparoscopic cholecystectomy.

\section{Case Presentation}

A 63-year-old woman presented with a two-day history of right-sided abdominal pain and swelling associated with dyspepsia. She had no history of jaundice. Abdominal examination revealed abdominal fullness on her right side with a palpable right iliac fossa mass. She was admitted for further examination. Blood tests showed high concentrations of inflammatory markers. She experienced an episode of pyrexia, requiring the commencement of intravenous (IV) antibiotics. A computed tomography (CT) scan of the abdomen demonstrated a markedly enlarged gallbladder (Figure 1). She was subsequently readmitted for an elective mini-laparoscopic cholecystectomy which was successful. Her postoperative recovery was unevenly and she was discharged at 24 hours postoperatively. A review at six weeks after discharge in the outpatient general surgery clinic was satisfactory. 


\section{Cureus}

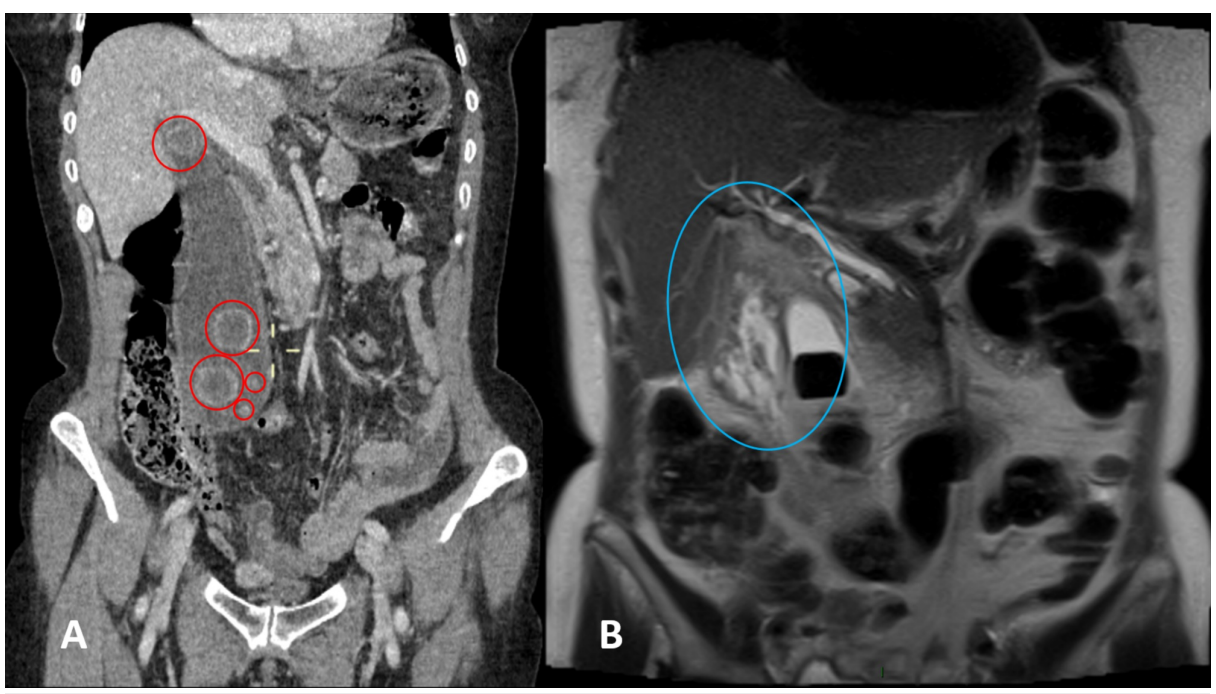

FIGURE 1: Abdominal computed tomography (CT) scan

Abdominal computed tomography showing a markedly enlarged gallbladder containing several stones measuring (red circles) $19.5 \times 5.4 \times 5.6 \mathrm{~cm}$ in the (A) craniocaudal, transverse and anteroposterior dimensions and in the (B) anatomical pelvis. Significant edematous changes in the area between the distended gallbladder with stones and the liver suggested gallbladder perforation (blue circle).

The removed gallbladder weighed $73.8 \mathrm{~g}$. Histologic examination showed an accumulation of

hemosiderophages within the wall mixed with foreign body type multinucleated giant cells, but no evidence of malignancy. The largest stone was cuboid and $27 \mathrm{~mm}$ in diameter.

\section{Discussion}

GGBs are very rare, with few such cases reported to date (Tables 1,2). There are no clear-cut parameters for differentiating a large gallbladder from a GGB [1,2]. Normal gallbladders are 7.5 to $10 \mathrm{~cm}$ in diameter, whereas some reported GGBs are $>14 \mathrm{~cm}$ [2]. Gallbladders $\geqslant 1.5 \mathrm{~L}$ (similar to or larger than an adult liver) have been defined as GGBs [2].

\begin{tabular}{|c|c|c|c|c|c|c|}
\hline Case report & Sex & Age (years) & Major comorbidity & GB size $(\mathrm{cm})$ & GB volume & Patient cystic duct \\
\hline Petit, before $1750[4]$ & $\mathrm{F}$ & $27-28$ & NR & NR & “2 pintes" (about 2 L) & Probable \\
\hline Van Swieten, 1754 [5] & M & 12 & Very probable & NR & "8 libras" (about 2.6 L) & Yes \\
\hline Collinson [6] & NR & NR & NR & NR & $12.5 \mathrm{~L}$ & NR \\
\hline Neudörfer, 1911 [6] & $\mathrm{F}$ & 50 & NR & NR & $5.25 \mathrm{~L}$ & Yes \\
\hline Kehr, 1913 [6] & NR & NR & NR & NR & $1.5 \mathrm{~L}$ & NR \\
\hline Borodach et al., $2005[7]$ & $\mathrm{F}$ & 67 & NR & $20 \times 12$ & $1.5 \mathrm{~L}$ & Yes \\
\hline Panaro et al., 2012 [8] & NR & 17 & PFIC-2 & $43 \times 21$ & $2.7 \mathrm{~L}$ & Yes \\
\hline Zong et al., 2013 [2] & $\mathrm{F}$ & 55 & NR & $30 \times 18$ & $4.0 \mathrm{~L}$ & Yes \\
\hline This case & $\mathrm{F}$ & 77 & NR & $24 \times 17$ & $3.3 \mathrm{~L}$ & Yes \\
\hline
\end{tabular}

TABLE 1: Case reports describing patients with GGB, including GB size and volume GB: Gallbladder; GGB: Giant gallbladder; F: Female; M: Male; NR: Not recorded. 


\section{Cureus}

\begin{tabular}{|c|c|c|c|c|c|}
\hline Case report & Sex & Age (years) & Size $(\mathrm{cm})$ & Obstruction & Postoperative diagnosis \\
\hline Grosberg, $1962\left[{ }^{[9]}\right]$ & $\mathrm{F}$ & 95 & $14 \times 5.5$ & Stone & Acute gangrenous cholecystitis, cholelithiasis \\
\hline Maeda et all, $1979[10]$ & $\mathrm{F}$ & 36 & $18 \times 4$ & No & Chronic cholecystitis, cholelithiasis \\
\hline Hsu et al., 2011 [11] & $\mathrm{F}$ & 87 & $16.4 \times 13.6 \times 7.8$ & No & Acute cholecystitis, gall bladder adenocarcinoma \\
\hline Panaro et al., 2013 [12] & NR & 17 & $43 \times 21 \times 20$ & No & Byler's disease \\
\hline
\end{tabular}

TABLE 2: Overview of reported cases of GGB

GGB: Giant gallbladder; F: Female; M: Male; NR: Not recorded.

A GGB may present initially as a cyst or tumor in the abdominal cavity, a finding usually atypical of gall bladder diseases [1]. The finding of a palpable right iliac fossa mass, as in the present patient, may elude the diagnosis of GGBs. Short-term intraluminal hypertension due to a tumor, such as a pancreatic tumor, obstructing the biliary tract, may cause a gallbladder to become enlarged [3,12]. In contrast, gallstones, which form over an extended period, may result in a shrunken, fibrotic gall bladder $[1,13]$.

GGBs may also be due to chronic obstruction, especially in patients with progressive conditions like malignancy [14]. This obstruction can induce chronically elevated intraductal pressure capable of producing an enlarged gallbladder. Stones can also cause intermittent obstructions, but these are regarded as not consistent enough to generate the chronic rise in intraductal pressure [14]. Chronic inflammation from stones may also result in the attenuation of the contractile function of the gallbladder, leading to further enlargement of an already distended gall bladder [15]. Acute blockage by migrating stones at the hepatic/cystic junction may also induce the growth of large gallbladders through a valve-like mechanism [2].

In addition to these obstructive mechanisms, GGBs may have other causes, including local hypoganglionosis within the gallbladder neck and other conditions allowing for the progressive enlargement of the gallbladder without clinical complications [1]. This patient reported in this study had gallstones.

A mini-laparoscopic cholecystectomy involves the use of small trocars and instruments, ranging from $2 \mathrm{~mm}$ to $3.5 \mathrm{~mm}$, similar to those used for conventional laparoscopic cholecystectomy. The operation in this patient used 3-mm trocars. Successful mini-laparoscopic cholecystectomy requires surgical experience and adaptation, more in patients with unusually sized gallbladders. The umbilical port served as a good route for extraction following an extension of this port by a few centimeters.

\section{Conclusions}

GGBs are rare, and their exact etiology and pathophysiology remain largely undetermined. No consensus has been reached on standardized definitions. GGBs can present as right iliac fossa masses containing multiple gallstones. Mini-laparoscopic cholecystectomy is effective and safe when performed by experienced surgeons.

\section{Additional Information}

\section{Disclosures}

Human subjects: Consent was obtained by all participants in this study. Conflicts of interest: In compliance with the ICMJE uniform disclosure form, all authors declare the following: Payment/services info: All authors have declared that no financial support was received from any organization for the submitted work. Financial relationships: All authors have declared that they have no financial relationships at present or within the previous three years with any organizations that might have an interest in the submitted work. Other relationships: All authors have declared that there are no other relationships or activities that could appear to have influenced the submitted work.

\section{References}

1. Kuznetsov AV, Borodach AV, Fedin EN, Khromova AD: Giant gallbladder: a case report and review of literature. Int J Surg Case Rep. 2014, 5:673-676. 10.1016/j.ijscr.2014.08.005

2. Zong L, Chen P, Wang L, He C, Wang G, Jiang J, Wang H: A case of congenital giant gallbladder with massive hydrops mimicking celiac cyst. Oncol Lett. 2012, 5:226-228. 10.3892/ol.2012.1010

3. Hagege A: Case of retention jaundice; importance of Courvoisier-Terrier law. (Article in French). Tunis Med. 1957, 45:439.

4. Petit JL: Oeuvres complètes. De Toutes de Librairies Médicales . Imprimerie de F. Chapoulaud, 1837.

5. Van Swieten G: Commentaria in Hermanni Boerhaave Aphorismos, de Cognoscendis et Curandis Morbis . 


\section{Cureus}

Pasquali, 1764 .

6. Kehr H: Chirurgie der Gallenwege. Ferdinand Enke Verlag, Stuttgart; 1913.

7. Borodach AV, Borodach VA, Kim AN: Gigantskaya Vodyanka Zhelchnogo Puzyrya. Sibirskiy Universitet, Novosibirsk; 2005.

8. Panaro F, Chastaing L, Navarro F: Hepatobiliary and pancreatic: giant gall-bladder associated with Byler's disease. J Gastroenterol Hepatol. 2012, 27:620. 10.1111/j.1440-1746.2012.07058.x

9. Grosberg SJ: Giant gallbladder. Am J Dig Dis. 1962, 7:1039-1040. 10.1007/bf02231907

10. Maeda Y, Setoguchi T, Yoshida T, Katsuki T: A giant gallbladder. Gastroenterol Jpn. 1979, 14:621-624.

11. Hsu KF, Yeh CL, Shih ML, Hsieh CB, Hsu HM: Giant gallbladder: adenocarcinoma complicated with empyema. J Trauma. 2011, 70:261. 10.1097/TA.0b013e31818c29fd

12. Verghese A, Dison C, Berk SL: Courvoisier's “law”-an eponym in evolution. Am J Gastroenterol. 1987, $82: 248-250$.

13. Woywodt A, Matteson E: Should eponyms be abandoned? Yes. BMJ. 2007, 335:424.

10.1136/bmj.39308.342639.AD

14. Fitzgerald JE, White MJ, Lobo DN: Courvoisier's gallbladder: law or sign?. World J Surg. 2009, 33:886-891. 10.1007/s00268-008-9908-y

15. Singal R, Gupta S, Singal RP, Mittal A, Sharma S, Khurana R: Gall bladder perforation leads to liver abscess formation - Role of ultrasonography. J Gastrointest Dig Syst. 2015, 5:279. 10.4172/2161-069X.1000279 